\title{
Craniofacial Morphology of Spinal Muscular Atrophy
}

\author{
K. HOUSTON, P. H. BUSCHANG, S. T. IANNACCONE, AND N. S. SEALE \\ Baylor College of Dentistry, Dallas, Texas 75246 /K.H., P.H.B., N.S.S/, and Texas Scottish Rite \\ Hospital for Children, Dallas, Texas 75219-3993 /S.T.I., N.S.S/
}

\section{ABSTRACT}

\begin{abstract}
Spinal muscular atrophy (SMA) is the second most common neuromuscular disease of childhood. It is the most common fatal recessive neuromuscular disease. This study is the first to evaluate the craniofacial growth of SMA patients. The results pertain to a sample of 25 SMA patients, between 5 and $32 \mathrm{y}$ of age, who were case matched with unaffected normal controls. Group differences for 25 measures, derived from tracings of standardized cephalometric radiographs, were evaluated using multivariate analysis of variance. The SMA group showed excessive vertical development, particularly of the lower face. They demonstrated relatively larger anterior than posierior facial heights, due in part to a smaller cranial base angulation and a more anteriorly positioned mandibular ramus. Anteroposterior skeletal discrepancies of SMA patients, due to
\end{abstract}

After the muscular dystrophies, SMA is the second most common neuromuscular disease of childhood. It has a prevalence of approximately one in 25000 live births (1). SMA is most commonly inherited as autosomal recessive, although sex-linked and dominant inheritance have been described. Death almost always ensues from respiratory failures caused by weak intercostal and diaphragmatic muscles (2). The severity of the disease corresponds to the distribution of muscle weakness; the proximal limb muscles are usually affected more than distal groups and the lower limbs more than upper. Muscle weakness and atrophy have been attributed to anterior horn cell degeneration, while bulbar symptoms result from involvement of the brainstem motor nuclei in some instance (3). It has recently been suggested that SMA may not be a degenerative disease (4). If this is so, then aggressive management of SMA could improve the expectancy and quality of life.

Some observers state that SMA does not affect the facial musculature $(2,5)$. However, evidence of feeding

Received August 6, 1993; accepted February 25, 1994.

Correspondence: Dr. P. H. Buschang, Baylor College of Dentistry, P.O. Box 660677, Dallas, TX 75266-10677.

Supported in part by the Muscular Dystrophy Association. the combined effects of a protrusive maxilla and a retrusive mandible, were moderate. The interincisal angle of the SMA group was smaller than normal, due primarily to proclined maxillary incisors. Relative to palatal length, the SMA group had smaller anterior cranial base and mandibular corpus lengths. These results suggest abnormal craniofacial growth patterns of SMA patients. The etiology of the observed abnormalities seems to be complex and multifaceted, but attention to the treatment of malocclusion may be important for optimal nutrition and respiratory function. (Pediatr Res 36: 265-269, 1994)

\section{Abbreviations \\ SMA, spinal muscular atrophy}

difficulties (3) and inability to suck through a straw (4) indicate otherwise. Because the size, shape, and position of craniofacial skeletal, cartilaginous, and dental tissues are influenced by masticatory muscle function (6-19), adaptive developmental modifications might serve as indirect evidence of muscle involvement.

Little is presently known concerning the adaptation of the craniofacial complex to neuromuscular disease. Dental and occlusal characteristics of subjects with myotonic dystrophy and Duchenne's muscular dystrophy reveal a significantly high prevalence of malocclusion $(20-27)$. Myotonic dystrophy also produces narrower faces, smaller cranial base angles, narrower and deeper palates, increased anterior facial height, more obtuse gonial angles, and altered mandibular shape $(25,27-31)$. The craniofacial morphology of children with SMA has not previously been described.

\section{METHODS}

Twenty-five white patients (11 males and 14 females) with a diagnosis of SMA were selected from muscle clinics at Texas Scottish Rite Hospital for Children, Dallas, Texas, and Children's Hospital, Cincinnati, Ohio. The diagnostic criteria for SMA have been previously 
reported (32). Each subject was gender and age matched to a healthy, untreated, control (of northern European ancestry) obtained from the longitudinal records of the Human Growth Research Center, University of Montreal (33). Matching effectively removes between-group variation in gender, age, and ethnicity.

Cephalometric radiographs were taken during the study or obtained (pretreatment films only) from private practicing orthodontists. The relevant skeletal structures and dentition were identified on each cephalogram and hand traced. A total of 21 landmarks were identified on each cephalometric tracing (Fig. 1), from which 26 linear and 17 angular measurements were computed. Replicates tracings of 15 cases show that method errors (34) range between 0.4 and $0.9 \mathrm{~mm}$ for the linear measures and between $0.4^{\circ}$ and $1.8^{\circ}$ for the angular measures. Because of 1) possible size differences between the SMA and control samples and 2) unavailability of all source/ subject/film distances necessary to adjust for magnification differences, proportionate analysis of the linear measures was conducted. To increase the power of the group comparisons, multivariate analyses of variance were used to compare the SMA and control groups.

\section{RESULTS}

The patients range between 5 and $32 \mathrm{y}$ of age; their median age was $9.5 \mathrm{y} ; 25 \%$ of the sample were under 8 $y$; and $75 \%$ of the sample were under $12 \mathrm{y}$ of age. The multivariate analysis of variance results showed that facial proportions were significantly different between the SMA and control groups (Table 1). Relative to posterior heights, anterior heights were 3-30\% larger for the SMA group than for the control group. Upper anterior to upper posterior height, as defined by the distances from nasion to anterior nasal spine and from sella to condylion, was especially long. Because the same relation based on the distance from sella to posterior nasal spine, rather than from sella to condylion, showed substantially smaller group differences, the condyle and glenoid fossa may have been more anteriorly positioned in the SMA sample.

Multivariate group differences in upper to lower facial proportions were highly significant $(p=0.003)$. Three of

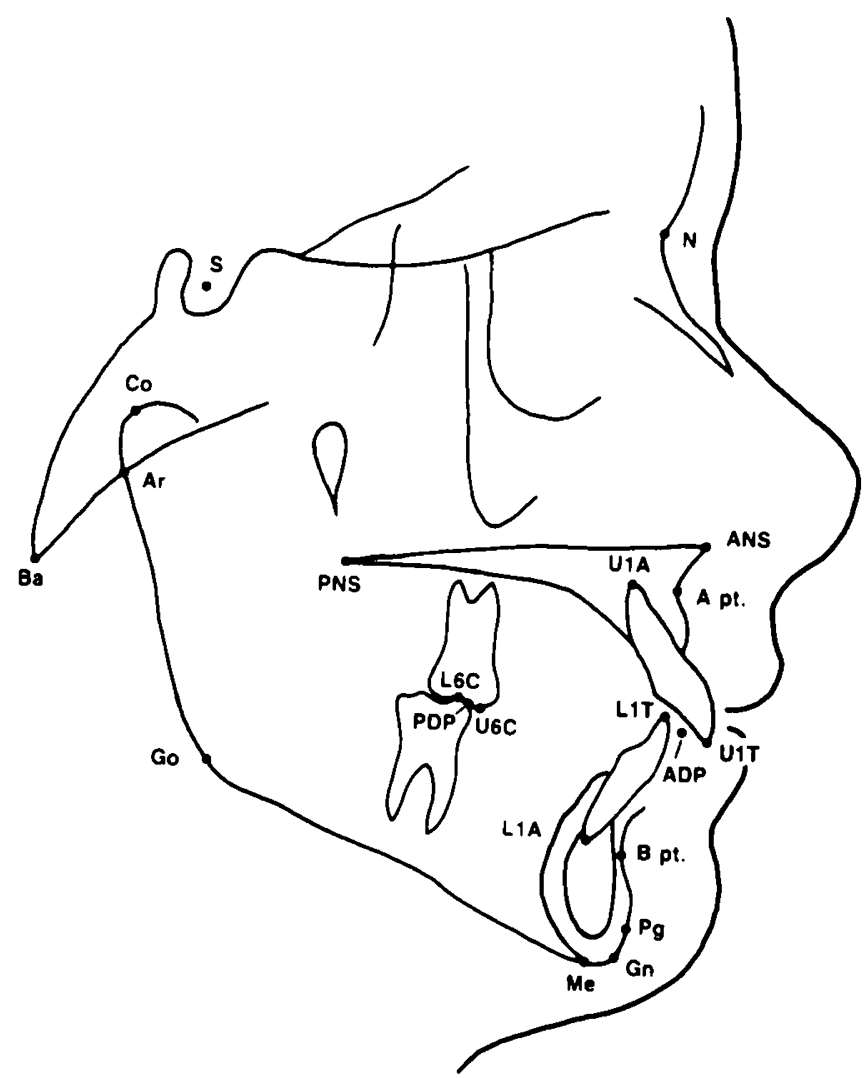

Figure 1. Cephalometric landmarks. $S$, sella; $N$, nasion; $P N S$, posterior nasal spine; $A N S$, anterior nasal spine; $U 1 A$, upper incisor apex; $A$ $p t$., A point; $U I T$, upper incisor tip; $A D P$, anterior Down's point; $P D P$, posterior Down's point; $U 6 C$, upper molar cusp; $L 6 C$, lower molar cusp; $L 1 T$, lower incisor tip; $L 1 A$, lower incisor apex; $B$ pt., B point; $\mathrm{Pg}$, pogonion; $\mathrm{Gn}$, gnathion; $\mathrm{Me}$, menton; $\mathrm{Go}$, gonion; $\mathrm{Ar}$, articulare; $\mathrm{Co}$, condylion; $\mathrm{Ba}$, basion.

the four measures demonstrated significant univariate differences. The results were consistent in showing that the upper face was 5-7\% shorter for the SMA group than for the controls.

Although the mandibular (sella to nasion/gonion to menton) and occlusal (sella to nasion/anterior Down's point to posterior Down's point) planes were approximately $2.5^{\circ}$ steeper in the SMA group than in the control group, the differences were not statistically significant (Table 2). This indicates a failure to attain significant

Table 1. Group comparisons and descriptive statistics for facial proportions*

\begin{tabular}{|c|c|c|c|c|c|c|c|c|}
\hline \multirow[b]{2}{*}{ Variable } & \multirow[b]{2}{*}{ Scale } & \multicolumn{2}{|c|}{ SMA } & \multicolumn{2}{|c|}{ Control } & \multicolumn{3}{|c|}{ Univariate } \\
\hline & & Mean & SD & Mean & SD & $F$ & $d f$ & $p$ \\
\hline \multicolumn{9}{|c|}{ Anterior/posterior facial proportions (multivariate $F=3.774, d f 4: 42, p=0.010$ ) } \\
\hline N-ANS/S-PNS & $\%$ & 110.5 & 11.6 & 107.3 & 5.8 & 1.460 & 1 & 0.233 \\
\hline ANS-Me/PNS-Go & $\%$ & 169.0 & 21.4 & 161.4 & 13.0 & 2.145 & 1 & 0.150 \\
\hline N-Me/S-Go & $\%$ & 162.0 & 14.7 & 159.6 & 9.4 & 0.414 & 1 & 0.523 \\
\hline N-ANS/S-Co & $\%$ & 252.2 & 50.6 & 222.5 & 23.3 & 6.783 & 1 & 0.012 \\
\hline \multicolumn{9}{|c|}{ Upper/lower facial proportions (multivariate $F=4.819$, df $4: 42, p=0.003$ ) } \\
\hline N-ANS/ANS-Me & $\%$ & 74.7 & 8.6 & 79.2 & 5.8 & 4.459 & 1 & 0.040 \\
\hline S-PNS/PNS-Go & $\%$ & 113.6 & 11.8 & 118.9 & 7.1 & 3.101 & 1 & 0.085 \\
\hline S-Co/PNS-Go & $\%$ & 50.8 & 8.3 & 57.6 & 4.6 & 11.415 & 1 & 0.002 \\
\hline S-Co/Ar-Go & $\%$ & 49.3 & 8.0 & 55.2 & 5.5 & 8.506 & 1 & 0.006 \\
\hline
\end{tabular}

${ }^{*} N$, nasion; ANS, anterior nasal spine; S, sella; PNS, posterior nasal spine; Me, menton; Go, gonion; Co, condylion; Ar, articulare. 
Table 2. Group comparison and descriptive statistics for craniofacial orientations*

\begin{tabular}{|c|c|c|c|c|c|c|c|c|}
\hline \multirow[b]{2}{*}{ Variable } & \multirow[b]{2}{*}{ Scale } & \multicolumn{2}{|c|}{ SMA } & \multicolumn{2}{|c|}{ Control } & \multicolumn{3}{|c|}{ Univariate } \\
\hline & & Mean & SD & Mean & $\mathrm{SD}$ & $F$ & $d f$ & $p$ \\
\hline \multicolumn{9}{|c|}{ Mandibular, occlusal, and palatal plant orientations (multivariate $F=0.956, d f 3: 42, p=0.595$ ) } \\
\hline S-N/Go-Me & degrees & 37.9 & 9.1 & 35.5 & 5.1 & 2.033 & 1 & 0.161 \\
\hline S-N/ADP-PDP & degrees & 20.0 & 7.2 & 17.5 & 3.3 & 2.282 & 1 & 0.138 \\
\hline S-N/ANS-PNS & degrees & 7.7 & 4.0 & 7.3 & 2.5 & 0.205 & 1 & 0.652 \\
\hline \multicolumn{9}{|c|}{ Cranial base and ramal orientation (multivariate $F=3.204$, df $4: 42, p=0.019$ ) } \\
\hline N-S-B pt & degrees & 127.3 & 6.4 & 130.8 & 3.9 & 5.171 & 1 & 0.028 \\
\hline N-S-Gn & degrees & 69.2 & 6.7 & 66.8 & 3.0 & 3.056 & 1 & 0.088 \\
\hline S-Ar-Go† & degrees & 144.3 & $(37.3-45.6) \dagger$ & 142.3 & 6.3 & 3.796 & 1 & 0.058 \\
\hline Ar-Go-Me & degrees & 129.9 & 4.6 & 131.5 & 4.8 & 1.021 & 1 & 0.318 \\
\hline
\end{tabular}

* S, sella; N, nasion; Go, gonion; Me, menton; ADP, anterior Down's point; PDP, posterior Down's point; ANS, anterior nasal spine; PNS, posterior nasal spine; B pt, B point; Gn, gnathion; Ar, articulare.

$\dagger$ Not normally distributed; median and interquartile range reported.

levels due to small sample size and relatively large between-subject variation.

Group differences in cranial base and ramal orientations were significant. The cranial base angle (nasion to sella to $B$ point) was more flexed in the SMA group than in the control group. In combination, the $y$ axis, articular angle (sella-articulare-gonion), and gonial angle (articulare-gonion-menton) indicated a more vertically oriented growth pattern.

Table 3 shows that the A point-nasion-B point angle, which describes anteroposterior relations of the maxilla and mandible, was approximately $2^{\circ}$ larger for the SMA group than for the control group. This difference was statistically significant.

Relative to anterior cranial base length (sella to nasion), mandibular corpus length (gonion to pogonion) was approximately $3 \%$ shorter and posterior cranial base length (sella to basion) was $8 \%$ shorter in the SMA group than in the control group. Palatal length (anterior nasal spine to posterior nasal spine), relative to corpus length, was approximately $3 \%$ longer in the SMA group.

The primary group differences for the dental inclinations pertained to the upper incisor, which was significantly more proclined (upper incisor tip to upper incisor apex/sella to nasion) in the SMA group than in the control group (Table 4). Its proclination accounted for most of the $9^{\circ}$ group difference in the interincisal angle; the lower incisors of the SMA group were only slightly proclined.

\section{DISCUSSION}

Houston et al. (35) showed that children with SMA have a significantly higher prevalence of malocclusion than expected. Their malocclusion was severe; it was characterized by molar distoclusion, anterior overjet, openbite, rotation and displacement of the posterior teeth, and maxillary lingual crossbite. The prevalence of malocclusion among the SMA group was at least as great as, if not greater than, previously reported for subjects with myotonic or Duchenne's dystrophy (20$27,36)$.

Subjects with SMA had a characteristic facies, which was clearly associated with their dental malocclusion (Fig. 2). They showed excessive vertical development, particularly of the lower face. Lengthening of the vertical facial dimensions has been associated with masticatory muscle weakness $(10,16,37)$. Adults with the "long face syndrome," for example, exert about half the masticatory force of adults with normal craniofacial morphology $(9,16,38)$. Vertical excess was also characteristic of myotonic dystrophy $(27,31,36)$.

Posterior facial height of the SMA group was relatively shorter than anterior height. These differences were primarily caused by the abnormal spatial position of the mandibular ramus, including the condyle. The ramus and condyle were positioned more anteriorly than expected in the SMA group, a finding that may be

Table 3. Group comparisons and descriptive statistics for horizontal relations*

\begin{tabular}{|c|c|c|c|c|c|c|c|c|}
\hline \multirow[b]{2}{*}{ Variable } & \multirow[b]{2}{*}{ Scale } & \multicolumn{2}{|c|}{ SMA } & \multicolumn{2}{|c|}{ Control } & \multicolumn{3}{|c|}{ Univariate } \\
\hline & & Mean & SD & Mean & SD & $F$ & $d f$ & $p$ \\
\hline \multicolumn{9}{|c|}{ Skeletal profile measurements (multivariate $F=3.235, d f 4: 42, p=0.021$ ) } \\
\hline A pt-N-B pt & degrees & 6.2 & 3.3 & 4.2 & 2.2 & 6.298 & 1 & 0.016 \\
\hline S-N-A pt & degrees & 82.6 & 6.5 & 81.4 & 3.3 & 0.714 & 1 & 0.402 \\
\hline $\mathbf{S}-\mathbf{N}-\mathbf{B}$ pt & degrees & 76.3 & 6.2 & 77.2 & 3.4 & 0.264 & 1 & 0.610 \\
\hline N-A pt-Pg & degrees & 169.3 & 7.5 & 172.2 & 4.8 & 2.606 & 1 & 0.113 \\
\hline \multicolumn{9}{|c|}{ Cranial base, maxillary and mandibular proportions (multivariate $F=3.285, d f 3: 43, p=0.030$ ) } \\
\hline $\mathrm{S}-\mathrm{N} / \mathrm{Go}-\mathrm{Pg}$ & & 98.1 & 7.2 & 101.3 & 6.9 & 3.137 & 1 & 0.083 \\
\hline ANS-PNS/Go-Pg & & 75.5 & 6.2 & 73.0 & 4.5 & 2.552 & 1 & 0.117 \\
\hline $\mathbf{S}-\mathbf{N} / \mathbf{S}-\mathbf{B a}$ & & 151.1 & 14.2 & 159.4 & 10.9 & 5.168 & 1 & 0.028 \\
\hline
\end{tabular}

\footnotetext{
* A pt, A point; N, nasion; B pt, B point; S, sella; Pg, pogonion; Go, gonion; ANS, anterior nasal spine; PNS, posterior nasal spine; Ba, basion.
} 
Table 4. Group comparisons (multivariate $\mathrm{F}=3.392$, df $3: 44$, $\mathrm{p}=0.026)$ and descriptive statistics for dental inclinations*

\begin{tabular}{|c|c|c|c|c|c|c|c|c|}
\hline \multirow[b]{2}{*}{ Variable } & \multirow[b]{2}{*}{ Scale } & \multicolumn{2}{|c|}{ SMA } & \multicolumn{2}{|c|}{ Control } & \multicolumn{3}{|c|}{ Univariate } \\
\hline & & Mean & $\mathrm{SD}$ & Mean & SD & $F$ & $d f$ & $p$ \\
\hline L1/Go-Me & degrees & 91.6 & 8.5 & 90.9 & 7.5 & 0.073 & 1 & 0.788 \\
\hline U1/L1 & degrees & 125.2 & 11.1 & 134.6 & 12.9 & 7.323 & 1 & 0.010 \\
\hline U1/S-N & degrees & 105.4 & 9.2 & 99.0 & 7.9 & 6.718 & 1 & 0.013 \\
\hline
\end{tabular}

* L1, lower incisor; Go, gonion; Me, menton; U1, upper incisor; S, sella; $\mathbf{N}$, nasion.

associated with or limited by the sample's smaller cranial base angles. Smaller cranial base angles have also been described for subjects with myotonic dystrophy $(28,31)$. The more forward position of the mandible may explain why the SMA sample showed only moderate anterior-posterior skeletal discrepancies between the maxilla and mandible, despite their reduced mandibular size.

The SMA patients also displayed flaring of the upper incisor, which was previously reported by Staley et al. (31) for myotonic dystrophy. Excessive flaring, which could account for some of the observed overjet and openbite (35), may be associated with a lack of pressure from the labial musculature.

Children with myotonic dystrophy also had craniofacial skeletal characteristics different from those identified for the SMA group. Kreiborg et al. (36), who followed a

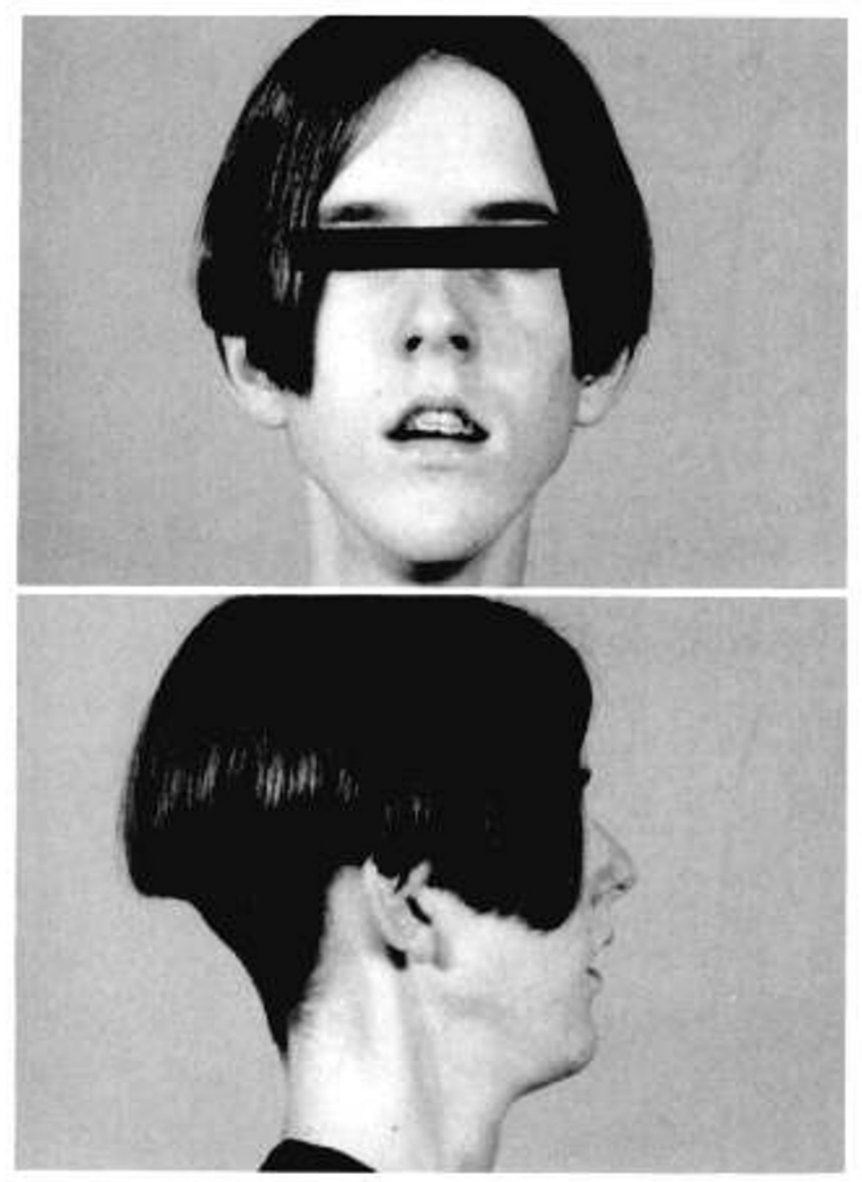

Figure 2. Facial appearance of a 15-y-old patient with SMA. patient with congenital muscular dystrophy from 4.7 to $12.6 \mathrm{y}$ of age, noted extreme backward rotation of the mandible and downward and backward rotation of the maxilla. The mandibular plane of the SMA group was steeper than expected, but because of the variability between subjects, the differences from normal were not significant. Kiliaridis et al. (27) showed that the weak masticatory muscles of 24 adult patients with myotonic dystrophy were associated with increased gonial angulation, divergent palatal and mandibular planes, and posterior rotation of the mandible. These characteristics were not clearly established for our SMA group. Kiliaridis et al. (27) also did not report any differences for the anteroposterior skeletal relations or the cranial base angulation. A recent report (31) of 23 subjects with myotonic dystrophy also identified significantly steeper mandibular plane angles, no differences in facial proportions, and a lack of anteroposterior skeletal (A point-nasion-B point) discrepancies.

We conclude that SMA patients have abnormal craniofacial growth patterns. Because of the many morphologic similarities between SMA and myotonic dystrophy, weakness of the masticatory muscles is implicated as a primary causative agent.

Skeletal disproportions and malocclusion in SMA might also be attributed to mouth breathing. Several of the components of malocclusion identified for SMA have also been reported for habitual mouth breathers without muscle disease (39). Most patients with SMA have abnormal pulmonary function. Thus, mouth breathing may be an attempt to decrease dead air space and increase ventilatory oxygen. The importance of decreased pulmonary function and its natural history in SMA is currently under investigation (40).

Because SMA patients tend to have poor head control secondary to weak neck flexors and extensors, habitual head posture may further account for some of the observed variability in craniofacial morphology $(41,42)$. Moreover, poor head control may contribute to upperairway obstruction, thereby exacerbating respiratory insufficiency. Thus, proper sitting posture and head support may ensure the patency of the upper airway, and more aggressive pulmonary management could decrease mouth breathing in SMA patients. More morphologic studies are needed to verify our results and to clarify the relationship between abnormal craniofacial growth patterns and pulmonary function.

Acknowledgments. This study would not have been possible without the assistance of Texas Scottish Rite Hospital and the Cincinnati Children's Hospital. Drs. Deborah Duffy and James Steiner were especially helpful in procuring data and coordinating the work accomplished in Cincinnati. Patients who participated in this study were recruited from the DCN-SMA Study Group (C. R. Buncher, Sc.D., F. Samaha, M.D., S. T. Iannaccone, M.D., B. S. Russmann, M.D., J. D. Cook, M.D., M. White, M.S., and C. McLaughlin). 


\section{REFERENCES}

1. Kunci RW, Crawford TO, Rothstein JD, Drachman DB 1986 Motor neuron diseases. In: Asbury AK, McKhann GM, McDonals WI (eds) Diseases of the Nervous System: Clinical Neurobiology. Ardmore Medical Books. Philadelphia

2. Merlini L, Granata C, Dubowitz V 1989 Current Concepts in Childhood Spinal Muscular Atrophy. Springer-Verlag. Vienna

3. Brooke RH 1977 A Clinician's View of Neuromuscular Diseases. Williams \& Wilkins, Baltimore

4. Russman BS, Iannaccone ST, Buncher CR, Samaha FJ, White M, Perkins B, Zimmerman L, Smith C, Burhans K. Barker L 1992 Spinal muscular atrophy: new thoughts on the pathogenesis and classification scheme. J Child Neurol 7:347-353

5. Dubowitz V 1964 Infantile muscular dystrophy. A prospective study with particular reference to a slowly progressive variety. Brain 87:707-718

6. Watt DG, Williams CHM 1951 The effects of the physical consistency of food on the growth and development of the mandible and the maxilla of the rat. Am J Orthod 37:895-928

7. Moore WJ 1965 Masticatory function and skull growth. J Zool 146:123-131

8. Möller E 1966 The chewing apparatus: an electromyographic study of the action of the muscle of mastication and its correlation to facial morphology. Acta Physiol Scand 69(suppl 28()):1-229

9. Ringquist M 1973 Isometric bite force and its relation to dimensions of the facial skeleton. Acta Odontol Scand $31: 35-42$

10. Ingervall B, Helkimo E 1978 Masticatory muscle force and facial morphology in man. Arch Oral Biol 23:203-206

11. Beecher RH, Corruccini RS 1981 Effects of dietary consistency on craniofacial and occlusal development in the rat. Angle Orthod 51:61-64

12. Bouvier M, Hylander W 1982 The effect of dietary consistency on morphology of the mandibular condylar cartilage in young macaques (Macaca mulatta). In: Dixon AD, Sarnat BG (ed) Factors and Mechanisms Influencing Bone Growth. University of California Press, Los Angeles, pp 569-579

13. Bouvier M, Hylander W 1984 The effect of dietary consistency on gross and histologic morphology in the craniofacial region of young rats. Am J Anat 170:117-126

14. Corruccini R, Beecher R 1982 Occlusal variation related to soft diet in a nonhuman primate. Science 218:74-76

15. Corruccini R, Beecher R 1984 Occlusofacial morphological integration lowered in baboons raised on soft diet. J Craniofac Genet Dev Biol 4:135-142

16. Proffit WR. Fields HW, Nixon WL 198.3 Occlusal forces in normal- and long-face adults. J Dent Res 62:566-571

17. Hinton R 1986 Secondary cartilage growth at the rat intermaxillary suture in response to changes in masticatory function. Anat Rec 214:55A(abstr)

18. Hinton R, Carlson DS 1986 Response of the mandibular joint to loss of incisal function in the rat. Acta Anat 125:145-151

19. Kiliaridis S 1986 Masticatory muscle function and craniofacial morphology. An experimental study in the growing rat fed a soft diet. Swed Dent J Suppl 36:1-189

20. Brown JC, Losch PK 1939 Dental occlusion in patients with muscular dystrophy. Am J Orthod Oral Surg 25:1()4(1-1(1)46

21. Futterman MJ 1940) Dental anomalies associated with pseudohypertrophic muscular dystrophy. Dent Outlook 27:73-78
22. Cohen Jr MM 1975 Congenital, genetic, and endecrinologic influences on dental occlusion. Dent Clin North Am 19:499-514

23. Stenvik A. Storhaug K 1986 Malocelusion patterns in fourteen children with Duchenne's muscular dystrephy. J Dent Child 53:215 218

24. Morinushi T, Mastumoto $S 1986$ Oral findings and a proposal for a dental health care program for patients with Duchenne type muscular dystrophy Spec Care Dentist 6:117-119

25. Gazit E. Lieberman M 1986 Form and function of the stomatognathic system in myotonic dystrophy. 62nd Congress of the European Orthodontic Society. $44($ abstr)

26. Ghafari J, Clark RE, Shofer FS, Berman PH $198 \times$ Dental and occlusal characteristics of children with neuromuscular disease. Am J ()rthod Dentofac Orthop 93:120-132

27. Kiliaridis S. Mejersjo C. Thilander B 1989 Muscle function and eraniofacial morphology: a clinical study in patients with myotonic dystrophy. Eur J Orthod 11:1.31-1.38

28. Lee KF, Lin SR. Hodes PJ 1972 New roentgenologic findings in myotonic dystrophy. Am J Roentgenol Radium Ther Nucl Med 115:179-185

29. Pryse-Phillips W, Johnson GJ, Larsen B 1482 Incomplete manifestation of myotonic dystrophy in a large kinship in Labrador Ann Neurol 11:58?-591

30. Vilmann HM, Juhl M. Kirkehy $S 1985$ Bone-muscle interactions in the muscular dystrophic mouse. Eur J Orthod 7:185-192

31. Staley RN, Bishara SE, Hanson JW, Nowak AJ 1992 Craniofacial develop ment in myotonic dystrophy. Cleft Palate Craniofac J 29:456-4t2

32. Cook JD, Jannaccone ST, Russman BS, Samaha F, Buncher RR, Ross D, Hare M. Smith C. Perkins B. Zimmerman L. Barker L. Burhans K. Newman R. White M, Bender J, Mclaughlin ( 1990 Cooperative study for the assess ment of therapeutic trials for the spinal muscular atrophies: a methodelogy to measure the strength of SMA patients. Muscle Nerve 13:7-10

33. Demirjian A. Brault Dubuc M, Jenick M 1971 Etude comparative de la croissance de lenfant canadien d'origine francais a Montreal. Can J Public Health 62:111-119

34. Dahlberg G 1940 Statistical Methods for Medicine and Biological Students. George Allen and Unwin. london

35. Houston K, Buschang PH, Duffy D, Iannaccone ST, Scale S 1944 Occlusal status of children with spinal muscular dystrophy. J Pediatr Dent (in press)

36. Kreiborg S, Jensen BL, Möller E, Björk A 1978 Craniofacial growth in at case of congenital muscular dystrophy. Am J Orthod 74:2017-215

37. Ingervall B. Bitsanis $\mathrm{E} 1987 \mathrm{~A}$ pilot study of the effects of masticatory muscle training on facial growth in long-face children. E:ur J Orthod $4: 1,5-23$

38. Sassouni V 1969 A classification of skeletal facial types. Am J Orthod $55: 109-123$

39. Subtelny JD, Subtelny JD 1973 Oral habits: studies in form, function and therapy. Angle Orthod 43:347-383

4). Samaha FJ, Buncher CR, Russmann BS, White M, lannaccone ST, Barker I. Burhans K. Smith C. Perkins B. Zimmerman L 1994 Pulmonary function in spinal muscular atrophy. J Child Neurol (in press)

41. Solow B. Tallgren A 1976 Head posture and craniofacial morphology. Am J Phys Anthrop 4:417-435

42. Cole SC 1988 Natural head position, posture and prognathism: the (hapman Price essay, 1986. Br J Orthod 15:227-234 